\title{
Amelanotic Cellular Blue Nevus: An Unusual Iris Localization
}

\author{
Silvana Guerriero, ${ }^{1}$ Lorenza Ciracì, ${ }^{1}$ Tiziana Tritto, ${ }^{1}$ \\ Maria Grazia Fiore, ${ }^{2}$ and Domenico Piscitelli ${ }^{2}$ \\ ${ }^{1}$ Department of Neurosciences and Sense Organs, University of Bari, Piazza Giulio Cesare 11, 70124 Bari, Italy \\ ${ }^{2}$ Department of Pathological Anatomy, University of Bari, Piazza Giulio Cesare 11, 70124 Bari, Italy
}

Correspondence should be addressed to Silvana Guerriero, silvanaguerriero@gmail.com

Received 17 June 2012; Accepted 19 July 2012

Academic Editors: D. Goldblum and D. K. Roberts

Copyright (C) 2012 Silvana Guerriero et al. This is an open access article distributed under the Creative Commons Attribution License, which permits unrestricted use, distribution, and reproduction in any medium, provided the original work is properly cited.

The authors describe the first case of eye amelanotic cellular blue nevus reported in literature and discuss the main differential diagnosis.

\section{Introduction}

The blue nevus is a benign, usually solitary lesion which is characterized by a localized proliferation of melanocytes and is believed to represent an abnormal arrest in embryonal migration of neural crest melanocytes [1].

Blue nevi are most commonly found on the skin. Rare cases of common blue nevi have been reported in the vagina [2], the uterine cervix [3], the Mullerian tract [4], the spermatic cord [5], the oral mucosa $[6,7]$, the prostate [8], and the bronchus [9] in the brain [10] and in the lymph node [11]. No eye localizations are described in literature.

We report an unusual case of iris amelanotic cellular blue nevus in a young woman.

\section{Case Report}

A 37-year-old woman presented herself at the Ophthalmological Department for a left eye pupil deformity. The slit lamp microscopy revealed an iris neoformation in the inferior temporal quadrant of the iris. This neoformation caused pupil dyscoria and corectopia and uveal ectropion. The color of the neoformation was light pink and it was richly vascularized (Figures 1(a) and 1(b)). The Ultrasound Biomicroscopy examination showed a neoformation localized in the iris stroma, undefined within the normal iris tissue, occupying the iris corneal angle, but not seeming to invade the ciliary body (Figure 1(c)).
Iris fluorescent angiography showed new formed vessels with abundant leakage in the neoformation.

After a complete workup, in the suspicion of an uveal amelanotic melanoma, surgical excision of the neoformation was programmed. Before surgery, a laser photocoagulation of the temporal inferior retinal quadrant was performed to prevent retinal detachment.

Under general anesthesia a sector iridociclectomy and a pupilloplasty were performed.

Histologically the lesion was composed of a dense and diffuse proliferation of amelanotic cells nested in a nevoid pattern and surrounded by a dense fibrous stroma (Figure 2(a)).

The cells varied in morphology from short spindleshaped to dendritic one. The neoplastic proliferation involved the iris stroma and, focally, the contiguous ciliary body (Figure 2(b)). All cells showed uniform, oval, vesicular nuclei with finely dispersed chromatin and inconspicuous nucleoli. Neither mitotic figures, cellular atypia, or necrosis were present (Figure 2(c)). Immunohistochemical reactions were intensely positive for S-100 protein and HMB45 (Figure 2(d)), but negative for alfa smooth-muscle actin, desmin, and CD56. The MIB-1 labeling index was low (Ki67 less than $1 \%)$.

On the basis of morphologic and immunohistochemical features, the tumor was diagnosed as amelanotic cellular blue nevus. 


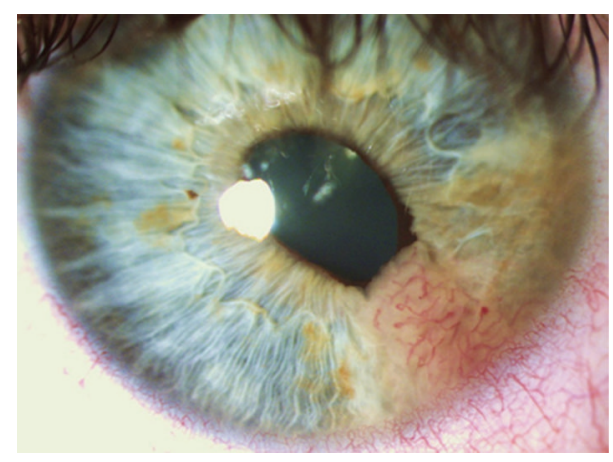

(a)

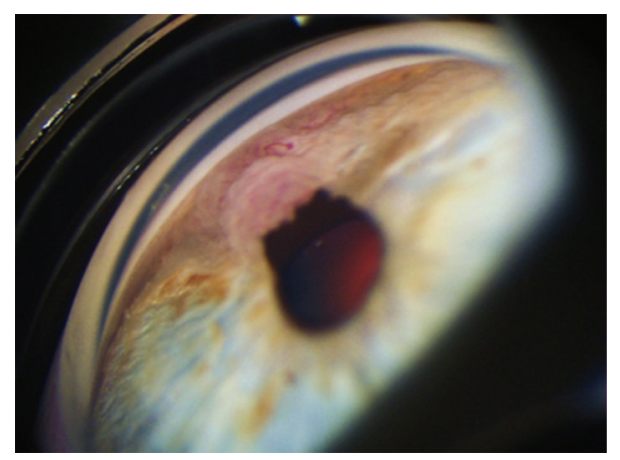

(b)

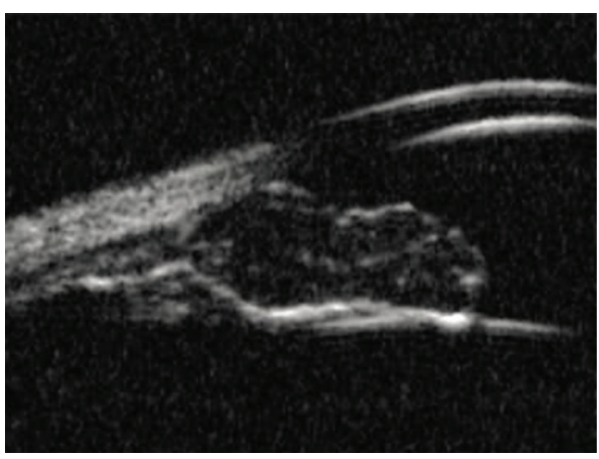

(c)

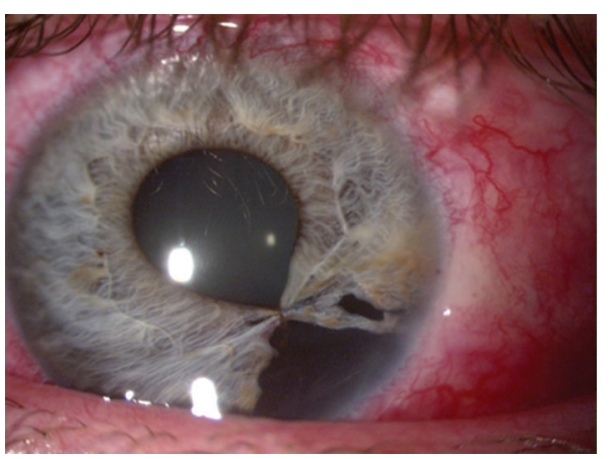

(d)

Figure 1: (a) Anterior segment of left eye showing an iris neoformation in the inferior temporal quadrant, richly vascularized. (b) Gonioscopic appearance of the neoformation. (c) UBM image showing a low reflectivity and poorly demarcated neoformation invading the iris stroma. (d) Postoperative appearance showing the sector iridociclectomy and the pupilloplasty.

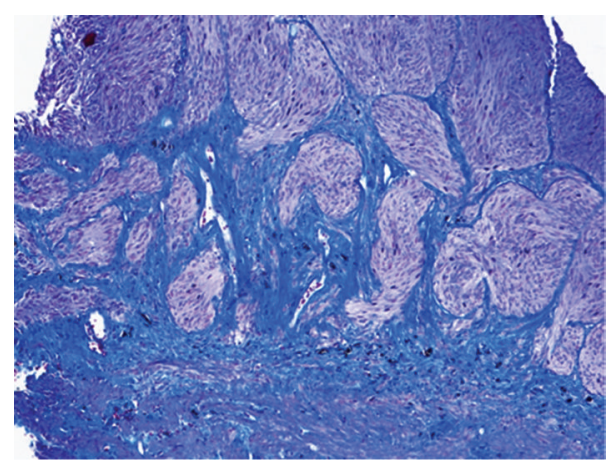

(a)

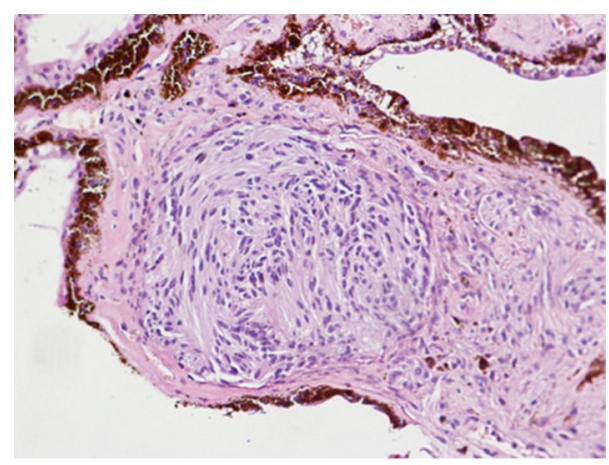

(b)

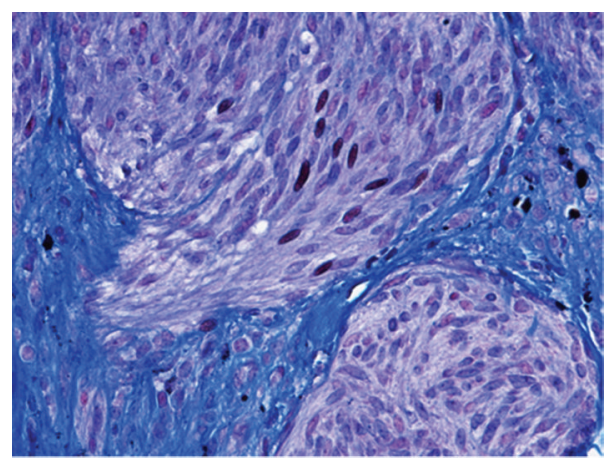

(c)

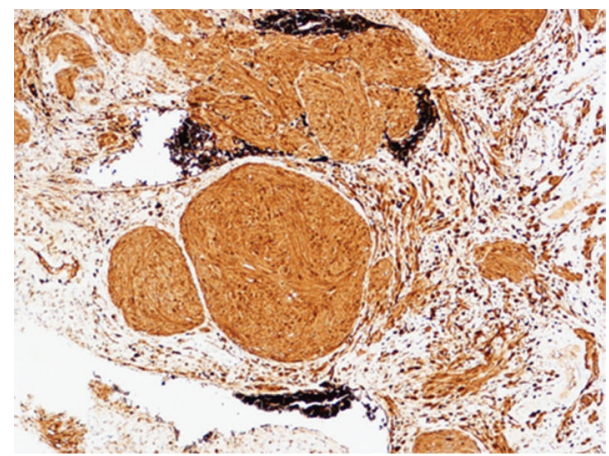

(d)

FIGURE 2: (a) Nests of unpigmented spindle cells in a fibrous stroma (Mallory stain, $\times 100$ ). (b) Neoplastic cells infiltrate the iris stroma $(\mathrm{H} \& \mathrm{E}, \times 200)$. (c) Uniform appearance of cellular morphology lacking in nuclear atypia and mitoses (Mallory stain, $\times 400$ ). (d) Immunohistochemical staining with HMB45 confirms the melanocytic nature of the neoplastic cells (original magnification, $\times 100)$. 


\section{Discussion}

Blue nevus was first described by Tièche in 1906 [12]. Earlier authors $[13,14]$ described similar lesions as chromatophoroma and melanofibroma. The common blue nevus is a flat to slightly elevated, smooth surfaced macule, papule, or plaque that is gray-blue to bluish black in color. Lesions are usually solitary and found on the head and the neck, the sacral region, and the dorsal aspects of hands and feet. Two varieties of blue nevi are described: the common blue nevus and the cellular type [1]. In common blue nevus, a vaguely nodular collection of poorly melanized spindled melanocytes and deeply pigmented dendritic melanocytes within thickened collagen bundles is seen. Scattered melanophages are usually noted. No mitoses are present. In cellular blue nevus, a well-defined nodule formed by fascicles and nests tightly packed, moderately sized, spindle shaped, and melanocytes with scattered melanophages are visible. Blue nevi may be divided into the following types: epithelioid blue nevus (classic description is with the Carney complex [15], but also without this condition), atypical blue nevi, deep penetrating blue nevi, sclerosing blue nevi, and amelanotic blue nevi [16]. Amelanotic cellular blue nevi with spindle cells is an unusual variant of the common and cell-rich blue nevus with atypical clinical and pathologic appearance due to the lack of pigment [17].

Differential diagnosis included all nonmelanocytic tumors with spindle cells [18].

In particular, amelanotic cellular blue nevus must be distinguished from malignant cellular blue nevus [19] and other variants of fusocellular melanomas, but also from mesectodermal leiomyoma [20], a rare benign tumor with double neurogenic and myogenic differentiation which takes origin from neural crests. The definitive diagnosis can be acquired with the aid of electron microscopy or with immunohistochemical study.

Our case is the first description of a blue amelanotic nevus involving the eye. Ophthalmologists must be aware of the possibility of this entity in the differential diagnosis of eye neoformations.

\section{Disclosure}

The authors declare that the paper is original, has not been submitted anywhere and all of them agree with the contents of it.

\section{Conflict of Interests}

The authors affirm that they have no financial support or conflict of interests with any biotechnology manufacturer having an interest in the subject matter or materials discussed in the submitted paper.

\section{References}

[1] P. A. Phadke and A. Zembowicz, "Blue nevi and related tumors," Clinics in Laboratory Medicine, vol. 31, no. 2, pp. 345358, 2011.
[2] V. A. Fitzhugh, K. Houck, and D. S. Heller, "Vaginal blue nevus: report of a case and review of the literature," Journal of Lower Genital Tract Disease, vol. 15, no. 4, pp. 325-327, 2011.

[3] K. Eskue, V. G. Prieto, and A. Malpica, "Cellular blue nevus of the uterus: a case report and review of the literature," International Journal of Gynecological Pathology, vol. 29, no. 6, pp. 583-586, 2010.

[4] K. J. Craddock, B. Bandarchi, and M. A. Khalifa, "Blue nevi of the Müllerian tract: case series and review of the literature," Journal of Lower Genital Tract Disease, vol. 11, no. 4, pp. 284289, 2007.

[5] R. Gonzalez-Campora, H. Galera-Davidson, F. J. VazquezRamirez, and S. Diaz-Cano, "Blue nevus: classical types and new related entities. A differential diagnostic review," Pathology Research and Practice, vol. 190, no. 6, pp. 627-635, 1994.

[6] S. Santos Tde, R. Frota, P. R. Martins-Filho, J. R. Cavalcante, C. Raimundo Rde, and E. S. Andrade, "Extensive intraoral blue nevus_case report," Anais Brasileiros de Dermatologia, vol. 86, no. 4, supplement 1, pp. S61-S65, 2011.

[7] A. S. Causeret, F. Skowron, A. M. Viallard, B. Balme, and L. Thomas, "Subungual blue nevus," Journal of the American Academy of Dermatology, vol. 49, no. 2, pp. 310-312, 2003.

[8] V. L. Dailey and O. Hameed, "Blue nevus of the prostate," Archives of Pathology and Laboratory Medicine, vol. 135, no. 6, pp. 799-802, 2011.

[9] L. K. Gilbey and C. E. Girod, "Blue rubber bleb nevus syndrome: endobronchial involvement presenting as chronic cough," Chest, vol. 124, no. 2, pp. 760-763, 2003.

[10] S. Nakano, K. Kinoshita, and Y. Morita, "Cellular blue nevus of the scalp associated with intracranial involvement," Surgical Neurology, vol. 27, no. 6, pp. 553-557, 1987.

[11] K. Scheller, C. Scheller, S. Becker, H. J. Holzhausen, and J. Schubert, "Cellular blue nevus (CBN) lymph node metastases of the neck with no primary skin lesion: a case report and review of literature," Journal of Cranio-Maxillofacial Surgery, vol. 38, no. 8, pp. 601-604, 2010.

[12] M. Tièche, "Über benigne Melanome ("Chromatophorome") der Haut-"blaue Naevi"," Virchows Archiv für Pathologische Anatomie und Physiologie und für Klinische Medizin, vol. 186, no. 2, pp. 212-229, 1906.

[13] S. W. Becker, "Cutaneous melanoma, a histologic study especially directed toward the study of melanoblasts," Archives of Dermatology, vol. 21, pp. 818-835, 1930.

[14] G. Miescher, "Melanom," in Handbuch Der Haut- Und Geschlechtskrankheiten, J. Jadassohn, Ed., vol. 12, p. 1005, Springer, Berlin, Germany, 1933.

[15] J. A. Carney and J. A. Ferreiro, "The epithelioid blue nevus: a multicentric familial tumor with important associations, including cardiac myxoma and psammomatous melanotic schwannoma," American Journal of Surgical Pathology, vol. 20, no. 3, pp. 259-272, 1996.

[16] W. D. James, T. Berger, and M. Dirk, Andrews' Diseases of the Skin: Clinical Dermatology, Saunders Elsevier, 2006.

[17] C. Moreno, L. Requena, H. Kutzner, A. De La Cruz, G. Jaqueti, and E. Sánchez Yus, "Epithelioid blue nevus: a rare variant of blue nevus not always associated with the Carney complex," Journal of Cutaneous Pathology, vol. 27, no. 5, pp. 218-223, 2000.

[18] R. L. Barnhill, M. A. Barnhill, M. Berwick, and M. C. Mihm, "The histologic spectrum of pigmented spindle cell nevus: a review of 120 cases with emphasis on atypical variants," Human Pathology, vol. 22, no. 1, pp. 52-58, 1991. 
[19] F. Aloi, A. Pich, and M. Pippione, "Malignant cellular blue nevus: a clinicopathological study of 6 cases," Dermatology, vol. 192, no. 1, pp. 36-40, 1996.

[20] L. Razzaq, E. A. Semenova, M. Marinkovic, R. J. de Keizer, S. G. Van Duinen, and G. P. Luyten, "Mesectodermal suprauveal iridociliary leiomyoma: transscleral excision without postoperative iris defect," Archives of Ophthalmology, vol. 129, no. 12, pp. 1635-1637, 2011. 


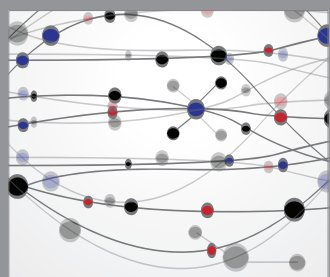

The Scientific World Journal
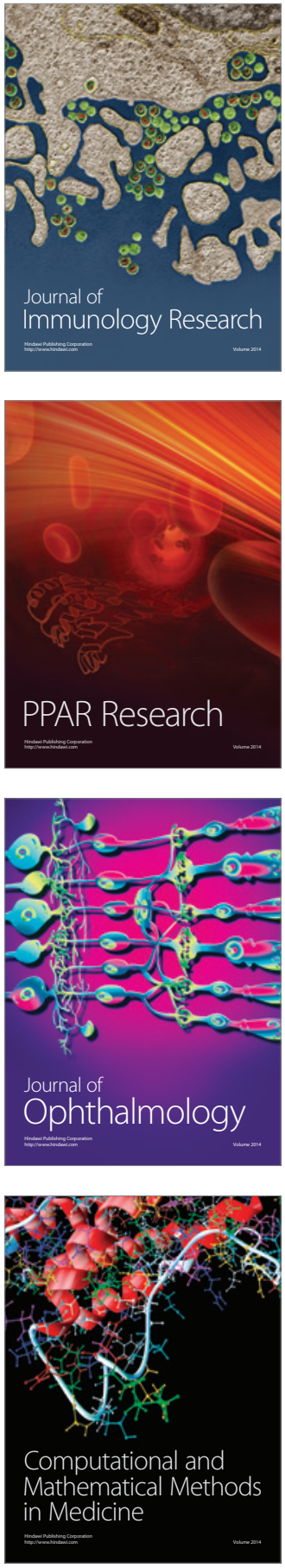

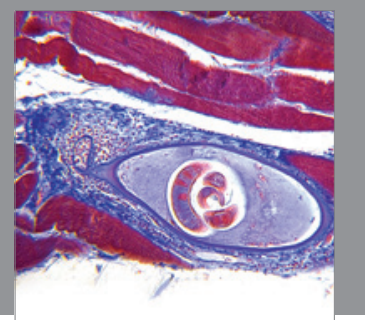

Gastroenterology

Research and Practice
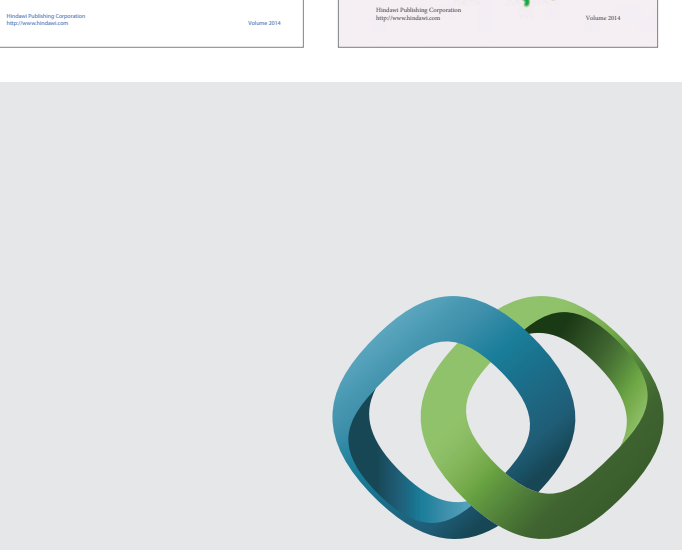

\section{Hindawi}

Submit your manuscripts at

http://www.hindawi.com
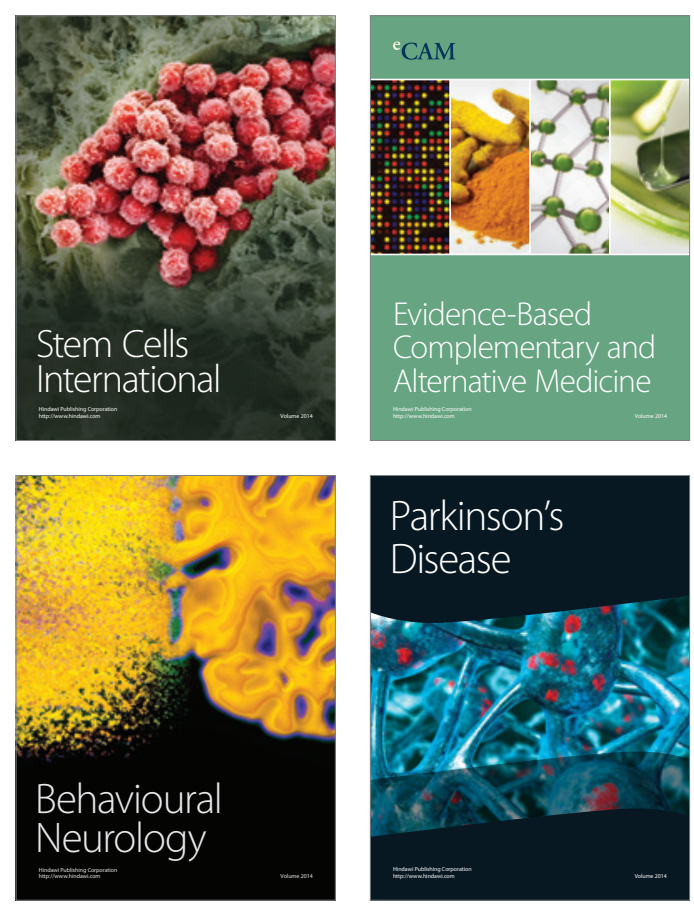

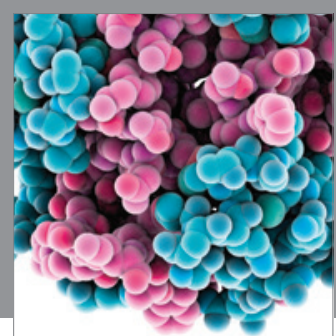

Journal of
Diabetes Research

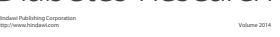

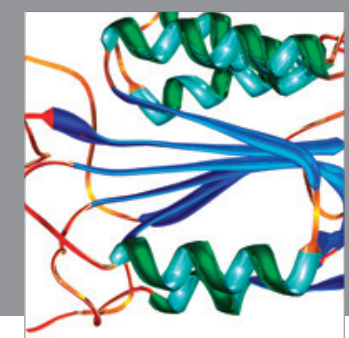

Disease Markers
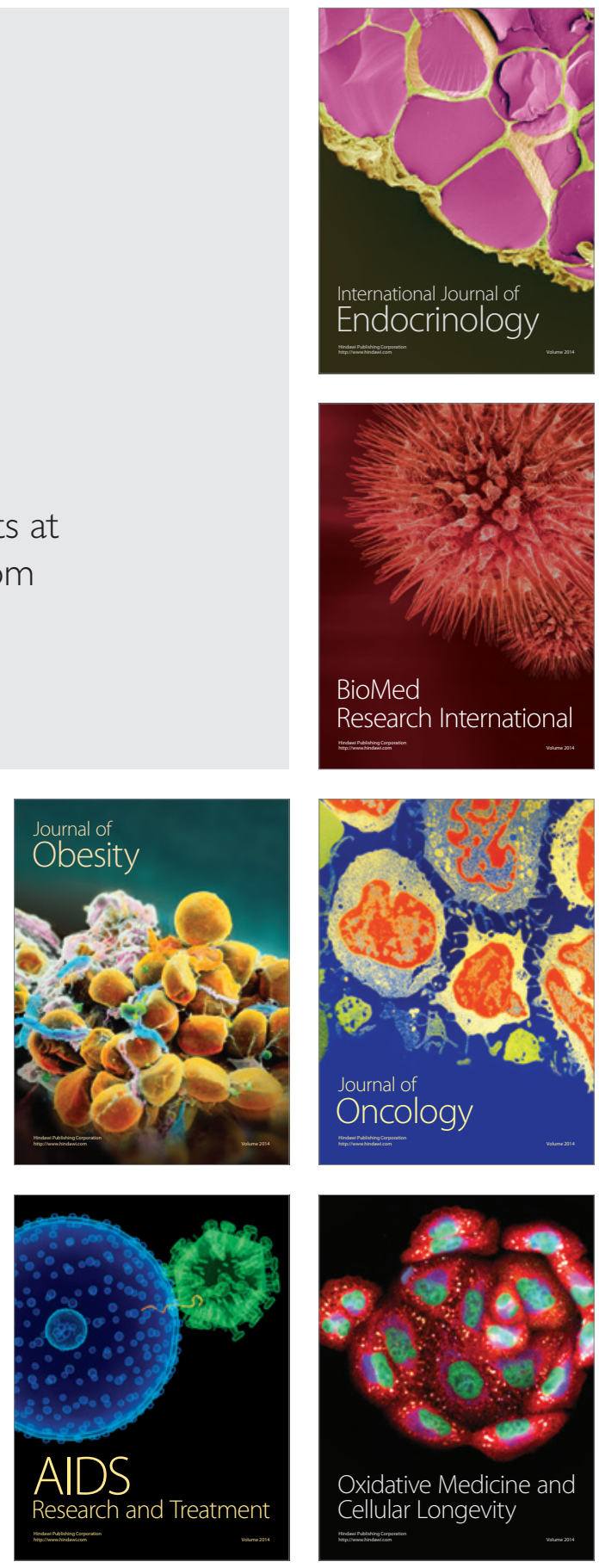